\title{
Fragilidade Júridica na Preservação do Patrimônio Ambiental e Cultural no Brasil: Estudo de caso da rota paleontológica do Rio Grande do Sul
}

\author{
Anna Ariane Araújo de Lavor ${ }^{1}$; Antônio Carlos Alves da Silva ${ }^{2}$; Mariana Emídio Oliveira Ribeiro ${ }^{3}$; Luciana Turatti ${ }^{4}$
}

Resumo: Este artigo se propôs a analisar a fragilidade jurídica na preservação do patrimônio ambiental e cultural brasileiro, à partir de um estudo de caso, através de uma pesquisa bibliográfica e de campo. Verificou-se que no Brasil existem diversas leis que protegem estes bens, porém com graves falhas na fiscalização, somadas às diversas ações protetivas mal planejadas, expondo o patrimônio público a uma destruição precoce. O presente artigo aborda diversas situações onde o resguardo do patrimônio e a sua fiscalização fracassaram e outras exitosas no intuito de preservação deste patrimônio.

Palavras-chave: Patrimônio, Preservação, Paleobotânico.

\section{Weakness in Legal Environmental Preservation of Cultural Patrimony and in Brazil: Case study of paleontological route from Rio Grande do Sul}

\begin{abstract}
This paper aimed to analyze the legal weakness in the preservation of Brazil's environmental and cultural patrimony, starting from a case study, through a literature search and field. It was verified that in Brazil several laws exist that protect these goods, but with serious failures in the inspection, added to the diverse badly planned protective actions, exposing the public patrimony to an early destruction. This article discusses various situations where the safeguarding of patrimony and inspection failed and other successful in preserving this heritage order.
\end{abstract}

Keywords: Patrimony, Preservation, Paleobotanical.

\section{Introdução}

Segundo Nunes (2011), o patrimônio de um povo consiste no legado do passado, assim como no que vivemos no presente e ainda o que passamos às gerações futuras. $\mathrm{O}$ patrimônio pode ser dividido em cultural, histórico e ambiental (natural).

A Constituição Federal (Brasil, 1988), dispõe que o patrimônio cultural consiste em todos os bens de natureza material e imaterial, individuais ou coletivamente, portadores de referência à identidade, à ação, à memória dos diferentes grupos formadores da sociedade

\footnotetext{
${ }^{1}$ Mestranda em Ambiente e Desenvolvimento pala UNIVATES. Contato: annaariane@ hotmail.com;

${ }^{2}$ Mestrando em Ambiente e Desenvolvimento pala UNIVATES. Contato: acas-acas@ hotmail.com;

${ }^{3}$ Mestranda em Ambiente e Desenvolvimento pala UNIVATES. Contato: mariana_meo@ hotmail.com;

${ }^{4}$ Doutorado em Direito pela UNISC. Docente do Programa de Pós-Graduação em Ámbiente e Desenvolvimento pala UNIVATES.

Contato: lucianat@univates.br
} 
brasileira. Para Zanirato e Ribeiro(2006) múltiplas paisagens, arquiteturas, tradições, gastronomias, expressões de arte, documentos e sítios arqueológicos são reconhecidos e valorizados como Patrimônio Cultural.

Conforme Delphim (2004) o patrimônio histórico é constituído pelo conjunto de bens existentes no país e cuja conservação seja de interesse público, devido a sua ligação a fatos históricos ou por apresentarem excepcional valor arqueológico, etnográfico, bibliográfico ou artístico.

Segundo a Lei 6938/81, o meio ambiente é considerado como um patrimônio público a ser necessariamente assegurado e protegido (Brasil, 1981). Para reforçar este status, a Constituição Federal, impõe tanto ao poder público, quanto à população, o dever de defendêlo e preservá-lo para as presentes e futuras gerações.

A defesa do patrimônio pode ser feita de diversas formas, conforme caso a caso e a Constituição Federal prevê a utilização de inventários, registros,vigilância, tombamento e desapropriação, e de outras formas de acautelamento e preservação (Brasil, 1988). Uma das formas mais adotadas é o tombamento, o qual segundo o Iphan (2017) é "o instrumento de reconhecimento e proteção do patrimônio cultural mais conhecido, e pode ser feito pela administração federal, estadual e municipal."

Ainda segundo o Iphan, o tombamento tem como objetivo impedir a destruição de um bem cultural, conservando-o para as gerações futuras. Contudo, segundo Delphim (2004), após o tombamento estes sítios podem sofrer impactos e sua possível descaracterização, normalmente devido ao turismo gerado.

Para Ghirardello e Spisso (2008), para garantir a preservação do patrimônio, o tombamento é necessário, pois é uma medida legal, conveniente e segura, principalmente para bens que se encontram ameaçados de destruição, proporcionado desta forma a sua plena utilização.

Por outro lado, a falta de proteção legal pode causar danos ligados a coletas sem as devidas orientações e vigilância, bem como as mais diversas depredações, causando destruição ao patrimônio, como podem ser observados nos relatos feitos por Jasper et al (2009), no Afloramento de Santa Quitéria -RS, o qual encontra-se sob responsabilidade apenas de seu proprietário, que não possui condições ou conhecimento técnico para ter o controle de visitas e de coletas no local. 
Outro exemplo desta falta de proteção pode ser observado nos afloramentos da Bacia Paraná, proximidades de Santa Maria - RS, onde as escavações e coletas são feitas sem fiscalização ou orientação do poder público, causando riscos de danificar o patrimônio local.

Conforme verificado na Figura 1, bem como segundo relatos de moradores locais,as pessoas que por ali passam geralmente param à margem do trecho da Rodovia Transbrasiliana, que liga Candelária/RS a Santa Maria/RS, e simplesmente pegam algum fóssil que estiver visível, devido a erosão natural provocado pela chuva e ventos.

Figura 1 - Afloramento da Bacia do Paraná, à margem da Rodovia Transbrasiliana

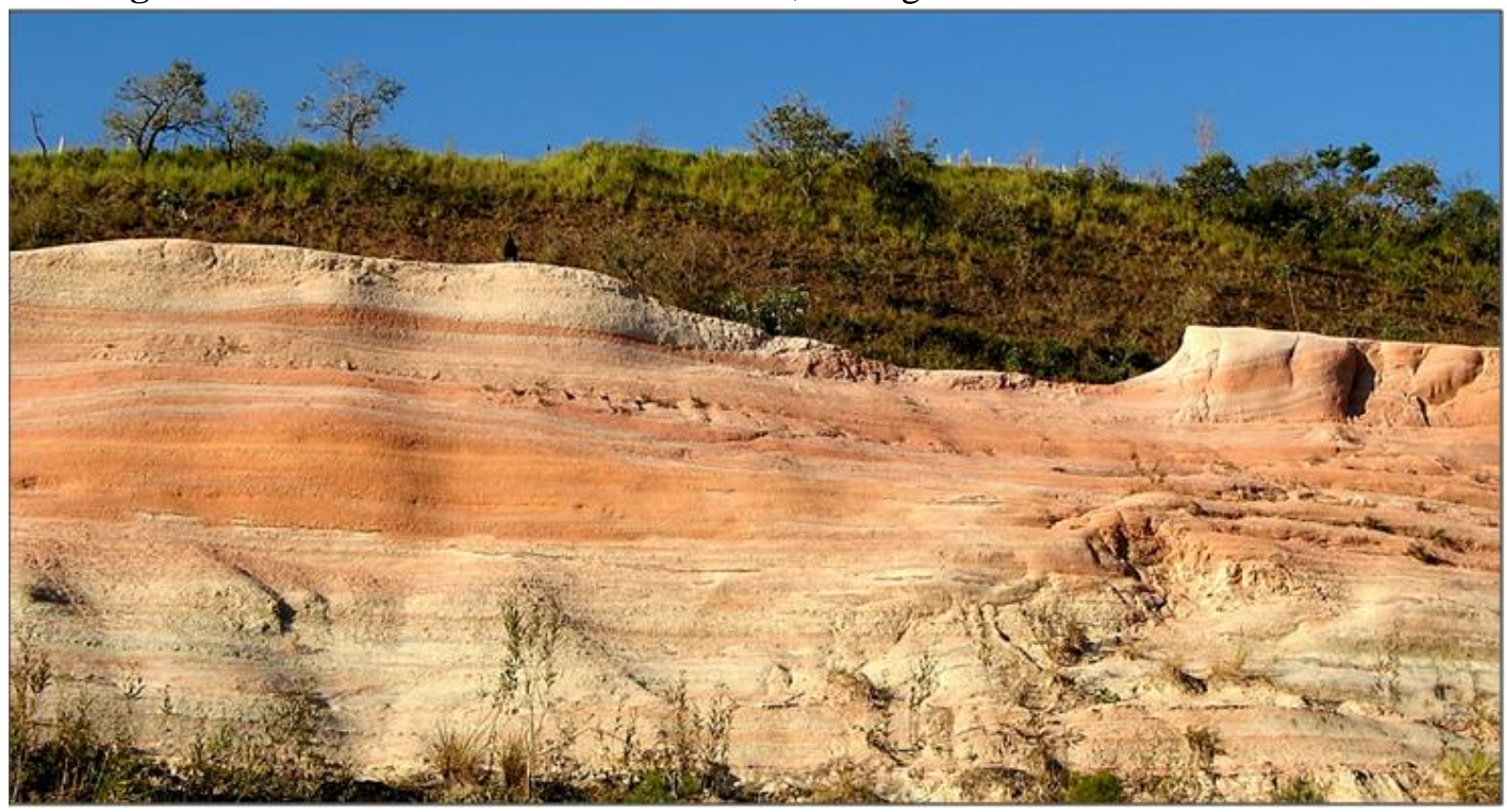

Fonte: Arquivo próprio

Mesmo este afloramento não fazendo parte da Rota Paleontológica, demarcada pela Secretaria de Turismo do Rio Grande do Sul, esta situação de fragilidade de preservação do patrimônio fóssil é uma realidade na região. Jasper et al (2009) quando estudaram o Afloramento de Quitéria, também localizado na Bacia do Paraná, no município de Encruzilhada do Sul/RS, analisaram a falta de proteção deste afloramento por parte dos poderes públicos, mas por outro lado verificaram a presença ativa do proprietário do imóvel na tentativa de preservação deste patrimônio, onde ele descreve que "até a década de 1990 ocorria no sítio a exploração de caulim a céu aberto, a qual, após se tornar inviável 
economicamente, foi abandonada, sendo o sítio mantido na atual condição de conservação por ações isoladas do proprietário" (JASPER et al., 2009, p. 452).

Neste sentido, Jasper et al (2009) consideram que neste caso do Afloramento de Quitéria em particular, a boa vontade do proprietário facilitaria a implantação de medidas para proteção do local com segue:

\begin{abstract}
Medidas que parecem adequadas e de fácil implantação são: tombamento do Afloramento (em contato com o proprietário, esta ação foi aventada, sendo muito bem recebida pelo mesmo); proteção e cercamento da área, principalmente da frente de lavra; abertura de novas frentes para fins de estudos científicos e didáticos; regulação dos processos de coleta por meio de visitas orientadas e acompanhadas por especialistas; integração dos dados das coleções que possuem espécimes provenientes do Afloramento Quitéria e organização de um cadastro único de material, para fins de viabilização de estudos posteriores.(JASPER et al., 2009, p. 462)
\end{abstract}

Neste sentido, percebe-se que nem todas as ações de preservação do patrimônio encontram resistência do setor privado, não necessitando assim de longos processos judiciais de desapropriação para uma ação efetiva de preservação e exploração destes locais. Daí nos indagamos: quais as fragilidades jurídicas, em termos de proteção do patrimônio ambiental, especificamente na rota paleontológica do Rio Grande do Sul?

\title{
Procedimentos Metodológicos
}

Trata-se de um estudo exploratório e descritivo, no sentido de se obter a percepção de fragilidade jurídica na preservação do patrimônio ambiental e cultural na rota paleontológica do Rio Grande do Sul.

A pesquisa qualitativa nos parece ser a que melhor se identifica com a análise do problema proposto. Para Chemin $(2015$, p. 56) uma pesquisa qualitativa deve tratar de uma "investigação de valores, atitudes, percepções e motivações do público pesquisado, com o objetivo principal de compreendê-los em profundidade".

As pesquisas exploratórias e descritivas tendem a "favorecer a familiaridade, o aumento da experiência e uma melhor compreensão do problema a ser investigado", além de "descrever as características de determinada população ou fenômeno, ou estabelecer relações entre variáveis" (CHEMIN, 2015, p. 58), pois foi necessário verificar e descrever diversas 
Id on Line Revista Multidisciplinar e de Psicoloqia

Id on Line Multidisciplinary and Psycology Journal

situações, para permitir uma análise e reflexão com maior clareza da situação de armazenamento de água, principalmente na região do nordeste brasileiro.

Portanto a pesquisa se caracteriza como um estudo de caso, com o intuito de conhecer um determinado grupo de pessoas ou região e suas características peculiares.

\section{Rota Paleontológica do Rio Grande do Sul}

A Rota Paleontológica no Rio Grande do Sul é definida pela Secretaria de Turismo do estado (2017) compreendendo diversos municípios, iniciando em Porto Alegre como Museu de Ciência e Tecnologia, da Pontifícia Universidade Católica - PUC/RS, passando por São João do Polêsine, Santa Maria, São Pedro do Sul e concluindo em Mata, como segue na figura 2.

Figura 2: Mapa do roteiro da Rota Paleontológica

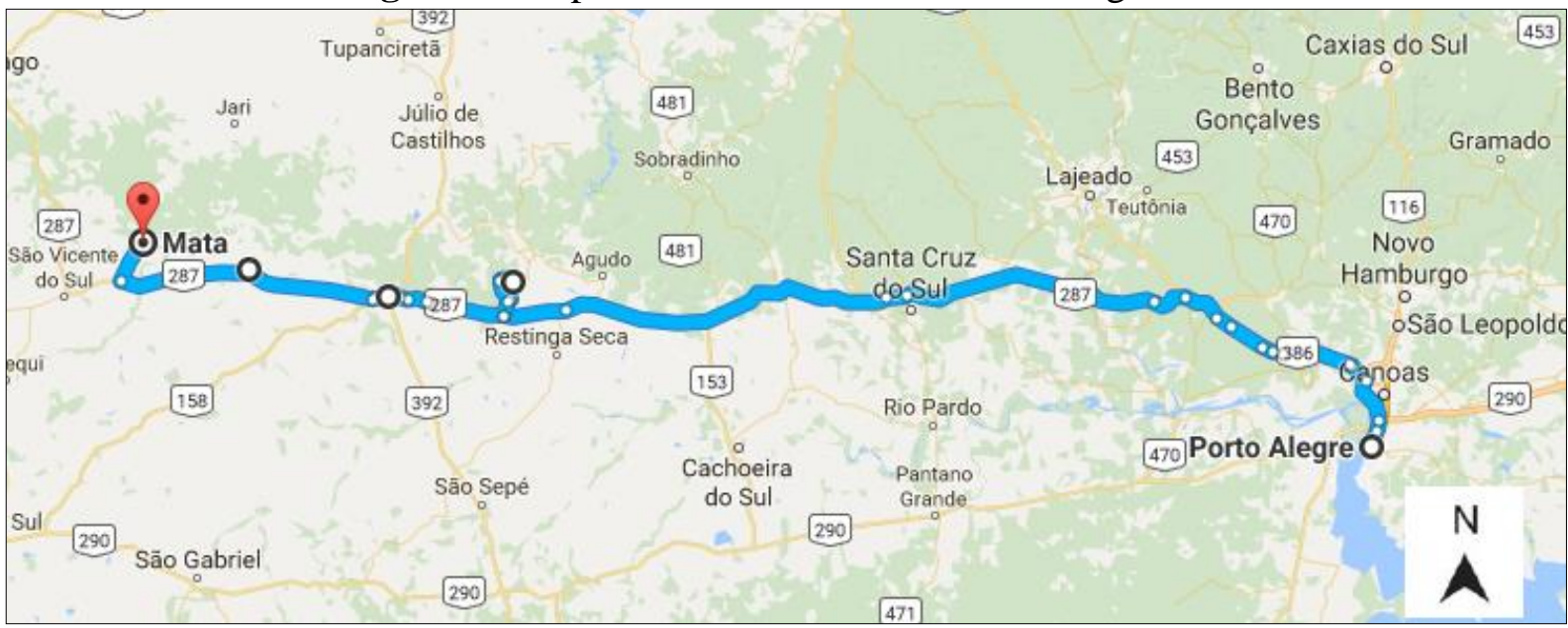

Fonte: Google Maps (2017)

Esta região é demarcada por Barberena et al (2002) na figura 3, como sendo a única região do Brasil onde tetrápodes triássicos têm sido encontrados, demonstrando a importância de proteção e exploração, tanto científica, quanto econômica destes locais, uma vez que representa uma parte única do patrimônio ambiental e cultural da humanidade, inserida no Brasil. 
Figura 3: Mapa de localização dos sedimentos triássicos no Rio Grande do Sul

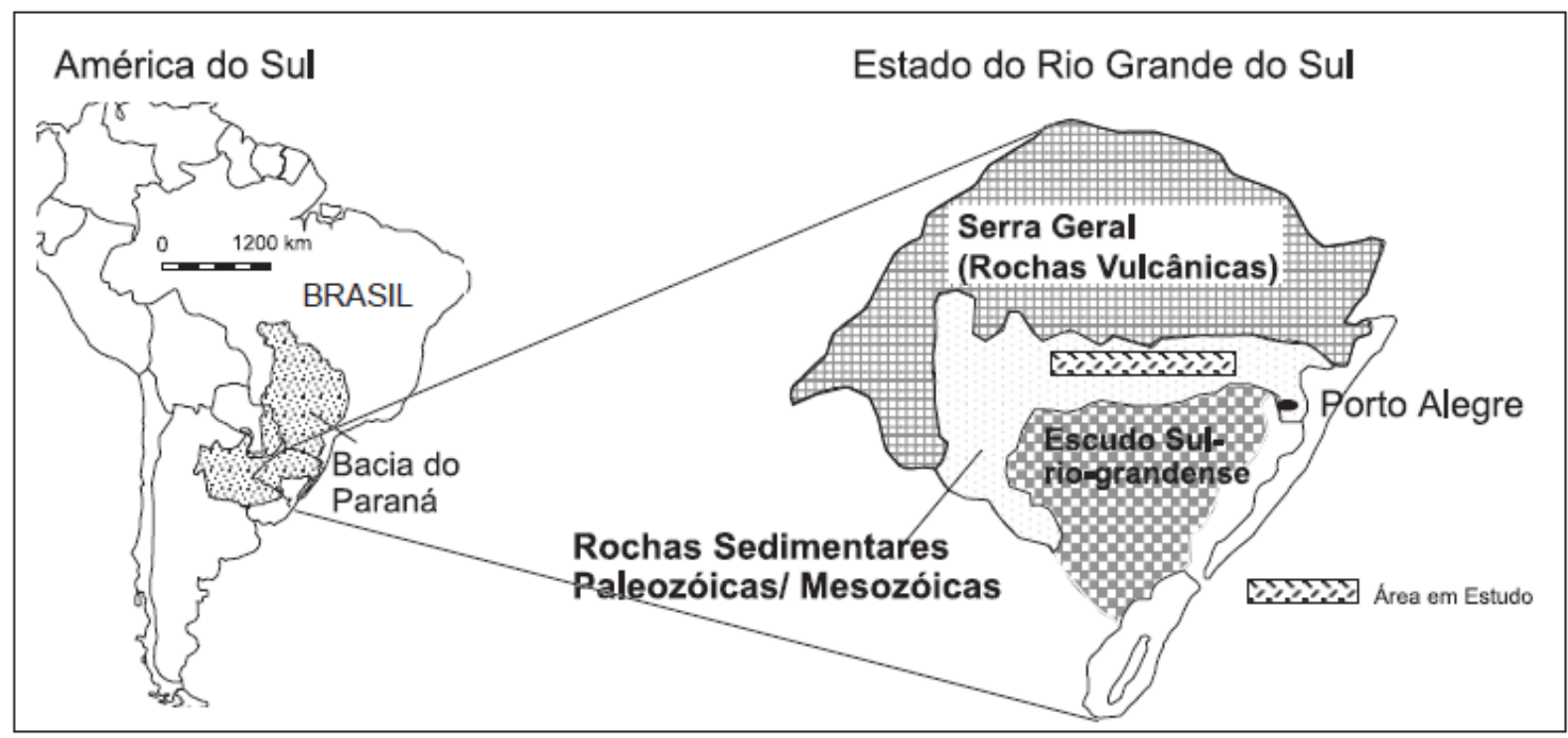

Fonte: (BARBERANA et al., 2002, p. 12)

Considerando que existem disparidades econômicas em relação aos municípios inseridos nesta rota, como por exemplo o PIB de 2014 (IBGE, 2017) de Santa Maria, R\$ 6.475.629 mil, em relação ao de Mata, R\$ 89.375 mil, mesmo considerando a questão demográfica, a capacidade orçamentária de um município investir na preservação deste espaços em relação ao outro é muito elevada, bem como o aparelhamento do estado nas suas secretarias de fiscalização, ficando os municípios menores na dependência de investimentos dos poderes Estadual e Federal. Deste modo foi selecionado neste estudo apenas os municípios de São Pedro do Sul e Mata, como segue.

\section{São Pedro do Sul}

Município localizado no centro-oeste do estado do Rio Grande do Sul, emancipado em 1944, com população total de 16.775 habitantes (IBGE, 2017), possui diversos afloramentos de fósseis provenientes de madeira, onde foram visitados dois destes locais, sendo o primeiro o Sítio Paleobotânico Piscina e o segundo foi o Sítio Arqueológico Pedra Grande. 
Id on Line Revista Multidisciplinar e de Psicoloqia

Id on Line Multidisciplinary and Psycology Journal

Na visita realizada ao Sítio Paleobotânico Piscina, que fica localizado às margens da rodovia BR-287, sendo que no local não existe nenhuma cerca de segurança ou algum funcionário, existindo apenas uma placa indicativa do local, que consta o dizer "Patrimônio Científico e Cultura; Protegido por Lei; Respeite - Cuide - Preserve". Mas conforme verificado na figura 4, o fóssil de um tronco de árvore está totalmente dilacerado.

Figura 4: Sítio Paleobotânico de Piscina, São Pedro do Sul

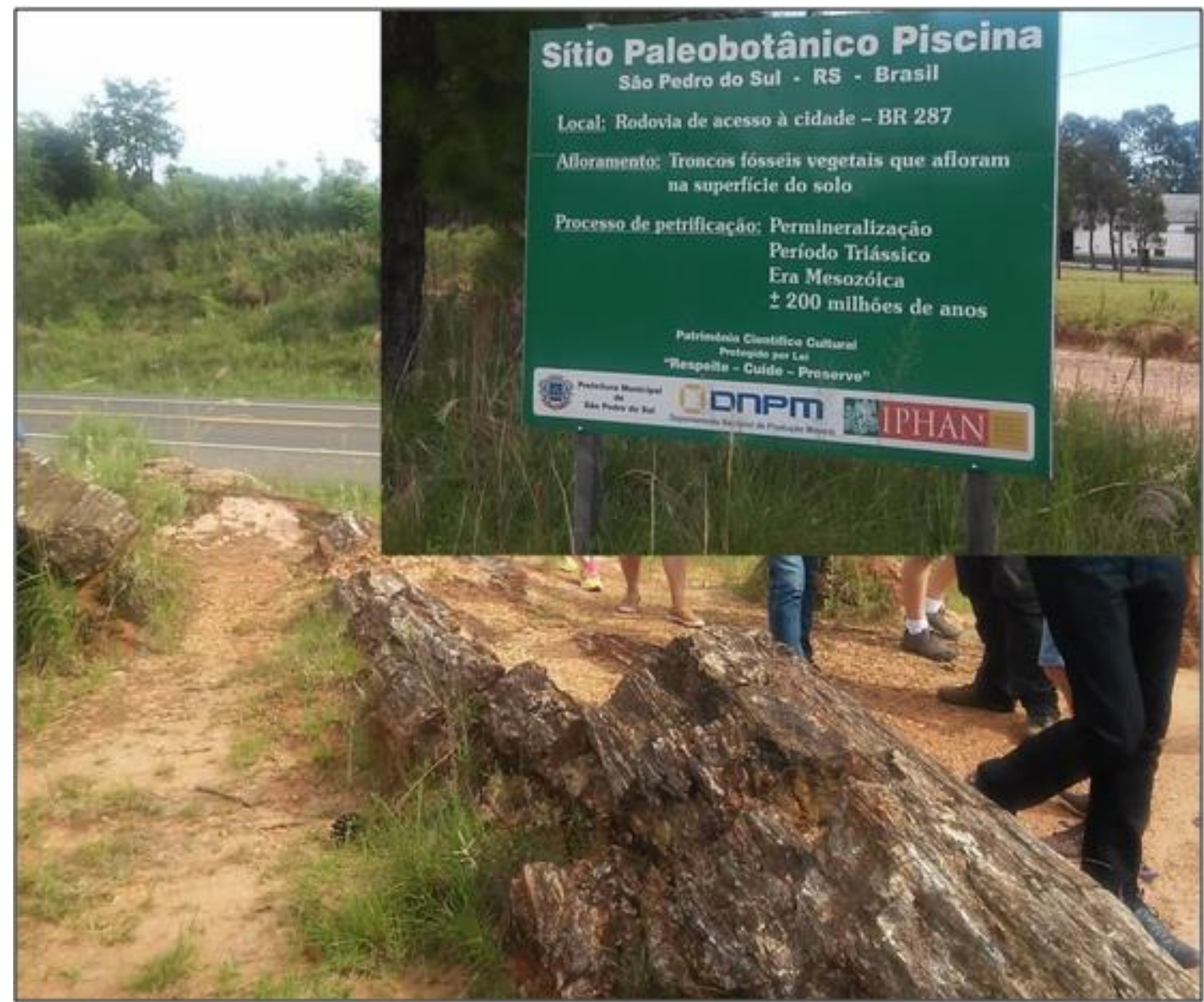

Fonte: Arquivo próprio

De acordo com o relato de pessoas que costumam visitar o local, o fóssil estava praticamente inteiro há alguns anos, mas com a facilidade de acesso, as pessoas que passam por ali e acham a pedra bonita, ou que simplesmente querem levar uma recordação do local, tiram um pedaço e o levam consigo, destruindo a percepção do fóssil original para os demais visitantes. Contudo, o Decreto n ${ }^{\circ} 4.146 / 1942$ no seu artigo primeiro afirma que "os depósitos 
Id on Line Revista Multidisciplinar e de Psicoloqia

Id on Line Multidisciplinary and Psycology Journal

fossilíferos são propriedade da Nação, e, como tais, a extração de espécimes fosseis depende de autorização prévia e fiscalização do Departamento Nacional da Produção Mineral" (BRASIL, 1942).

Neste sentido de que o tronco de árvore fossilizado é apenas um adorno, foi percebido também na Praça Crescêncio Pereira, localizado no centro da cidade conforme disposto na figura 5, totalmente descontextualizado, longe do seu local original e sem a devida proteção, servindo de bancos e trampolins para as crianças brincarem.

Figura 5: Praça Crescêncio Pereira, São Pedro do Sul

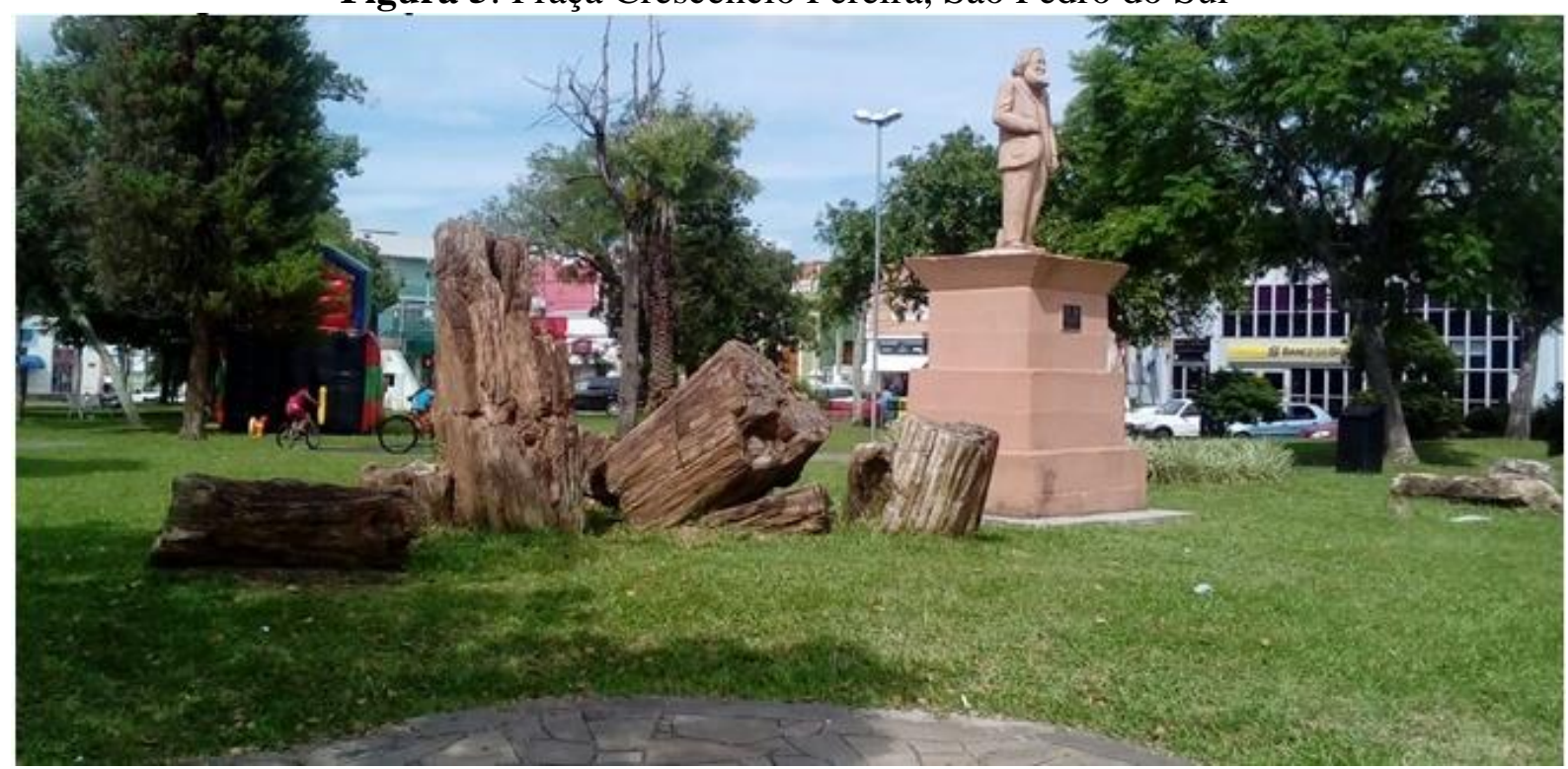

Fonte: Arquivo próprio

Mudando um pouco de contexto, na visita ao Sítio Arqueológico Pedra Grande, foi verificado uma organização maior do poder público, onde o sítio encontra-se totalmente cercado e protegido por um funcionário que recepciona os visitantes e lhes presta o mínimo de informação.

Mas ao mesmo tempo que foi verificado no momento da visita um baixo índice de visitação, que por sua vez pode estar relacionada a soma de dois fatores, sendo o primeiro, que o trajeto entre a BR-287 e o sítio não é pavimentado, o que provavelmente desestimula algumas pessoas em visitar o sítio, o segundo está relacionado a falta de publicidade no trajeto do local, bem como na própria cidade. 
Figura 6: Sítio Arqueológico Pedra Grande, São Pedro do Sul

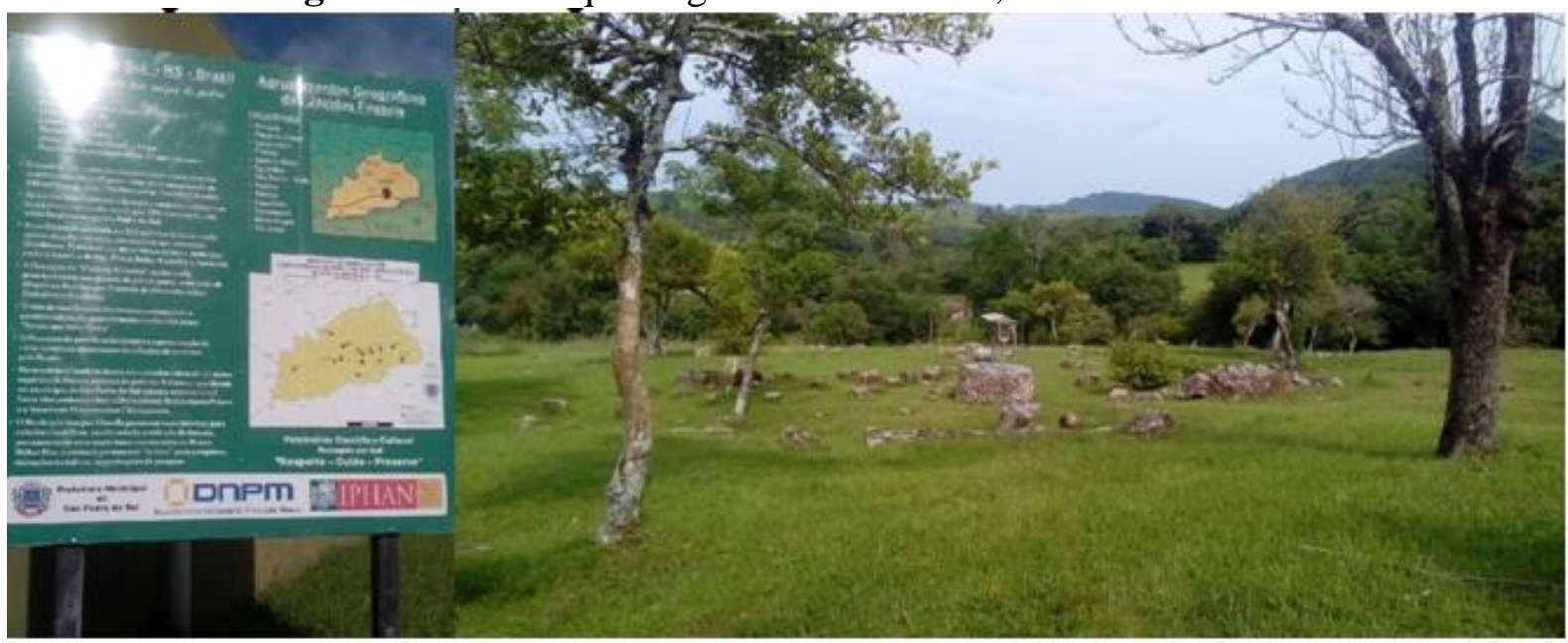

Fonte: Arquivo próprio

\section{Mata}

Mata está a 46km de distância de São Pedro do Sul, possui uma população de 5.141 habitantes (IBGE, 2017) e conta com uma história peculiar na relação entre os fósseis de madeira e a construção da cidade. De acordo com os recepcionistas do Museu Pe. Daniel Cargnin de Mata, a utilização dos fósseis para pavimentação e a construção das praças de Mata foram iniciadas com a chegada do Pe. Daniel Cargnin em 1976 no município de Mata.

Ressalta-se então que o Decreto $\mathrm{n}^{\circ} 4.146 / 1942$ no seu artigo primeiro afirma que "os depósitos fossilíferos são propriedade da Nação, e, como tais, a extração de espécimes fosseis depende de autorização prévia e fiscalização do Departamento Nacional da Produção Mineral" (BRASIL, 1942), portanto, as construções acima mencionadas infringiram esta legislação que já estava em vigor no período em que foram realizadas as extrações e aplicadas nas benfeitorias no município, demonstrando que a ineficiência do estado em proteger o patrimônio cultural é antigo, conforme a figura 7 a seguir: 
Figura 7: Fotos do município de Mata

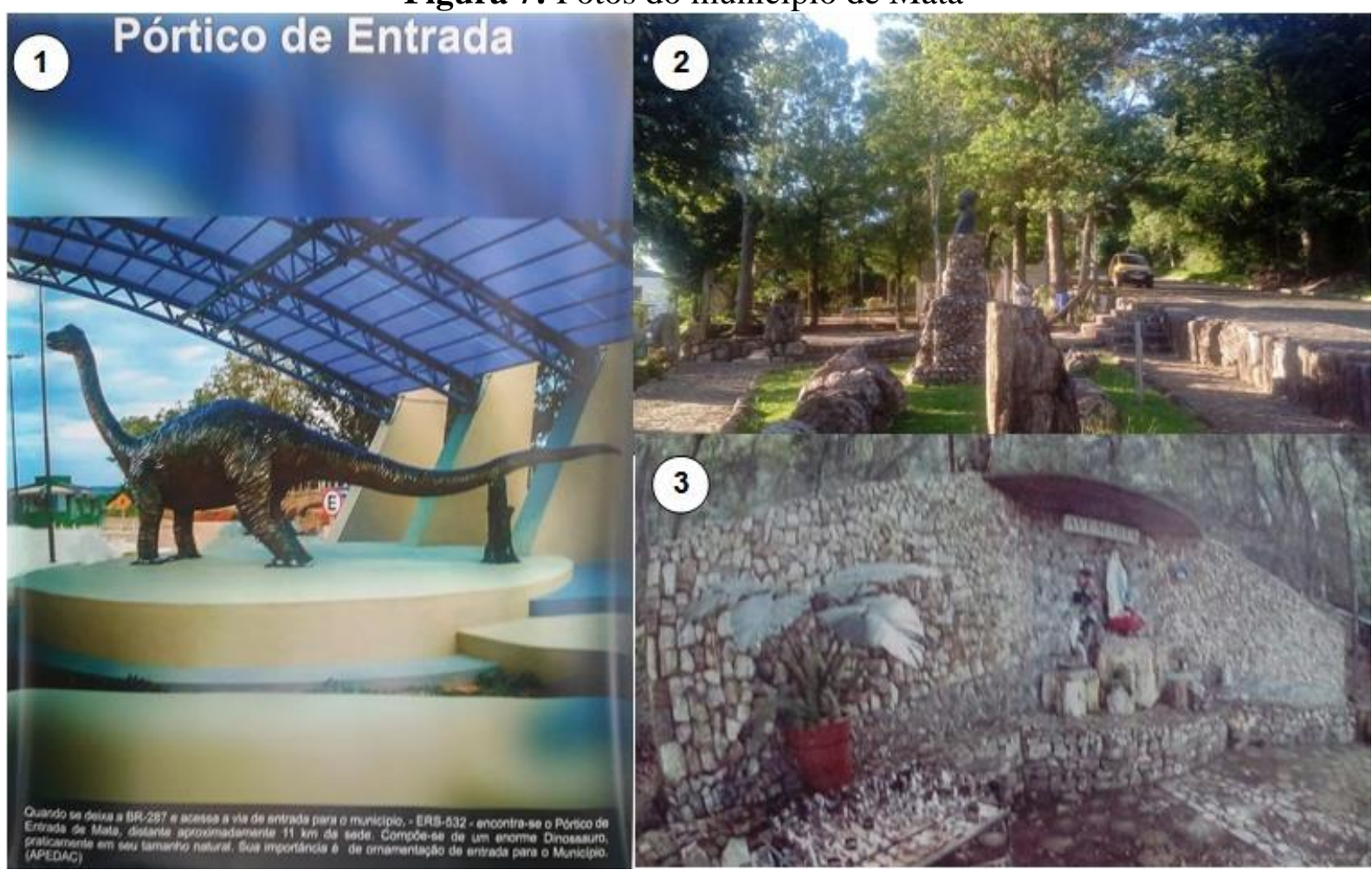

Fonte: Arquivo próprio

1- Cartaz exposto no Museu Pe. Daniel Cargnin em Mata, demonstrando o Pórtico da entrada da cidade; 2Praça em Mata com o busto do Pe. Daniel Cargnin; 3- Gruta de Nossa Senhora de Lourdes.

Deste modo a cidade ficou conhecida como "a cidade da pedra que foi madeira", mas de acordo com a foto 1, onde está o Pórtico da entrada da cidade de Mata, encontra-se um dinossauro que de acordo com o cartaz exposto no museu a estátua é "praticamente em seu tamanho natural", mas de acordo com Sommer e Scherer (2002), diversas expedições foram realizadas no município de Mata, mas não formam encontrados fósseis de dinossauros, ou seja, o planejamento de publicidade da cidade não retrata o que o próprio slogan diz que é "a cidade da pedra que foi madeira".

\section{Considerações Finais}

Ainda no Rio Grande do Sul, contudo, pode-se observar os sítios arqueológicos das Missões Jesuíticas Guarani e das Ruínas de São Miguel das Missões/RS, os quais são 
protegidos legalmente e reconhecidos pela UNESCO como Patrimônio Mundial (Brasil, 2014), devido a seu excepcional valor histórico e cultural.

Embora tenha ocorrido um pouco de descaracterização do local para fins turísticos, com um espetáculo de som e imagem, contado a história das Missões Jesuítas, é inegável que o zelo e a proteção legal conseguiram conservar de forma exemplar o patrimônio cultural local.

Figura 8: Sítio Arqueológico de São Miguel Arcanjo

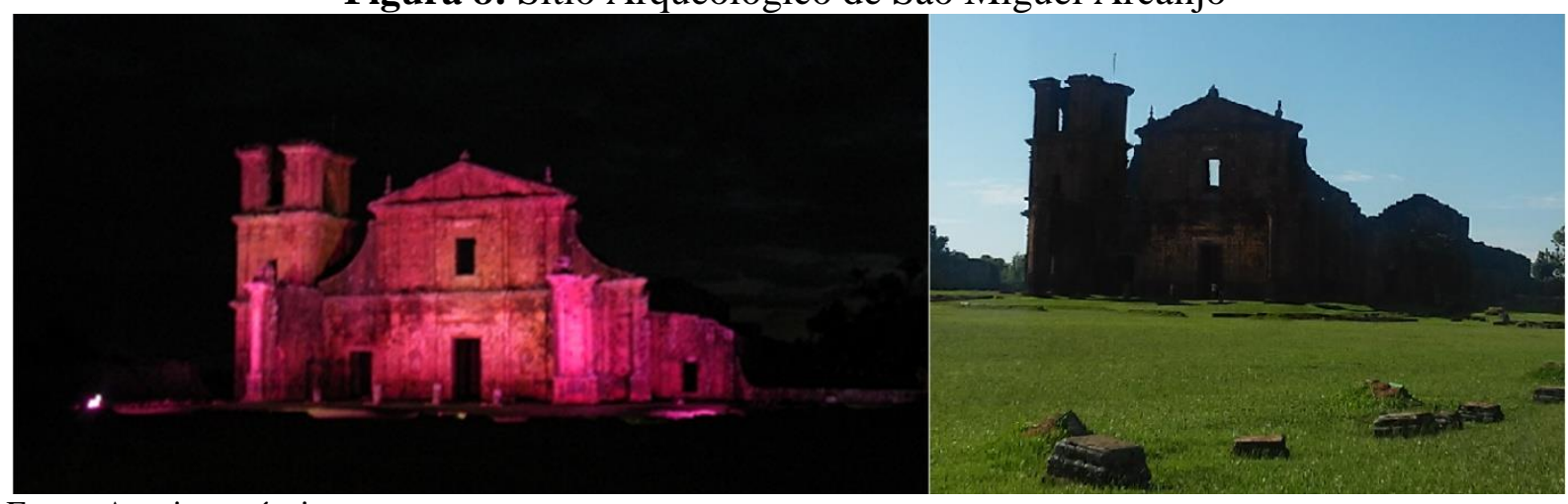

Fonte: Arquivo próprio

Sugestões para a efetiva proteção do Patrimônio: Conforme exposto, a proteção legal e reconhecimento de um bem como patrimônio ambiental, cultural ou histórico possa corrompê-lo através da exploração turística, pode-se concluir que esta ainda é a melhor forma de preservação para que as gerações futuras possam ter acesso ao valioso patrimônio existente. Assim, recomenda-se maior proteção legal ao patrimônio, principalmente através do tombamento, como forma de reconhecer "o valor histórico, artístico, paisagístico, arqueológico, bibliográfico, cultural ou científico de bens que, por isso, passam a ser preservados" (MARÉS, 1995).

Existe a obrigação legal destinada aos governos e suas instituições de formular políticas públicas, diretrizes e critérios para a implementação, acompanhamento, avaliação e monitoramento das ações, projetos e programas voltados a preservação do patrimônio nacional. Contudo, mesmo havendo farta legislação, deve-se destacar, que não existe eficácia na aplicação da lei, devido, principalmente, a falta de fiscalização e planejamento por parte do 
poder público, prejudicando a diversidade cultural, histórica e ambiental e consequentemente a garantia do desenvolvimento sustentável do país.

\section{Referências}

BARBERENA, M. C; ET AL. Tetrápodes Triássicos do Rio Grande do Sul - Vertebrados fósseis de fama mundial. In: Sítios geológicos e paleontológicos do Brasil. Org. In: SCHOBBENHAUS, C.; ET AL, Brasília : CPRM, v. 1, p. 11-22. 2002.

BRASIL, CONSTITUIÇÃO FEDERAL, 1988. Disponível em <http://www.planalto.gov.br/ ccivil_03/constituicao/constituicaocompilado.htm>. Acesso em 19/02/2017.

Decreto Lei no 4.146/1942. Disponível em <http://www.planalto.gov.br/ccivil_03/ decreto-lei/1937-1946/Del4146.htm>. Acesso em 26 de fevereiro de 2017.

Saiba quais bens brasileiros são patrimônio mundial cultural. 2014. Disponível em <http://www.brasil.gov.br/cultura/2009/10/saiba-quais-bens-brasileiros-sao-patrimoniomundial-cultural $>$. Acesso em 21/02/2017.

CHEMIN, Beatris F. Manual da Univates para trabalhos acadêmicos: planejamento, elaboração e apresentação. 3.ed. Lajeado: Univates, 2015. E-book. Disponível em: <http://www.univates.br/biblioteca>. Acesso em: 10 jul. 2017.

DELPHIM, C.F.M. O patrimônio natural no Brasil. Disponível em http://portal.iphan.gov.br/uploads/publicacao/Patrimonio_Natural_no_Brasil.pdf. Acesso em 20 de fevereiro de 2017

GHIRARDELLO, N.; SPISSO, B. Patrimônio histórico: como e por que preservar. BauruSP: Canal 6, 2008.

IBGE. Cidades. Disponível em < http://cidades.ibge.gov.br/v3/cidades/municipio/ 4316907> Acesso em 24 de fevereiro de 2017.

IPHAN. Bens Tombados.2017. Disponível em <http://portal.iphan.gov.br/pagina/ detalhes/126>. Acesso em 21/02/2017

JASPER. A; ET AL. Afloramento Quitéria, Encruzilhada do Sul, RS - Sedimentos lagunares com singular associação fitofossilífera da Formação Rio Bonito (Sítio 008). In: Sítios geológicos e paleontológicos do Brasil. Org. WINGE. M; ET AL, Brasília : CPRM, v. 2, p. 451-464. 2009.

MARÉS, C. F. S. F. A Defesa dos Interesses Difusos em Juízo, p. 167, $7^{\text {a }}$ edição, Ed. Saraiva, 1995. 
NUNES, R. S. UNESCO: Patrimônio Cultural Imaterial e Sociomuseologia. Dissertação apresentada para a obtenção do Grau de Mestre em Museologia no Curso de Mestrado em Museologia, conferido pela Universidade Lusófona de Humanidades e Tecnologias, 2011.

SECRETARIA DE TURISMO NO RIO GRANDE DO SUL.Um Grande Destino. Disponível em<http://www.turismo.rs.gov.br/roteiro/176/rotapaleontologica>.Acesso em 23 de fevereiro de 2017

SOMMER, M.G.; SCHERER, C.M.S.; et al. Sítios Paleobotânicos do Arenito Mata (Mata e São Pedro do Sul), RS - Uma das mais importantes "florestas petrificadas" do planeta. Org. In: SCHOBBENHAUS, C.; et al, Brasília : CPRM, v. 1, p. 3-10. 2002.

ZANIRATO, Silvia Helena; RIBEIRO, Wagner Costa. Patrimônio cultural: a percepção da natureza como um bem não renovável.Rev. Bras. Hist., São Paulo , v. 26, n. 51, p. 251262, June $2006 \quad$ Disponível em <http://www.scielo.br/scielo.php?script=sci_arttext\&pid=S010201882006000100012\&lng=en\&nrm=iso>. Acesso em 20 de fevereiro de 2017.

Como citar este artigo (Formato ABNT):

LAVOR, Anna A.A. de; SILVA, Antônio Carlos A. da; RIBEIRO, Mariana E. O.; TURATTI, Luciana. Fragilidade Júridica na Preservação do Patrimônio Ambiental e Cultural no Brasil: Estudo de caso da rota paleontológica do Rio Grande do Sul. Id on Line Revista Multidisciplinar e de Psicologia, 2017, vol.11, n.37, p. 213-225. ISSN: 1981-1179.

Recebido: 18.08 .2017

Aceito: 18.08 .2017 